\title{
Collection Development and Management
}

\section{An Overview of the Literature, 2011-12}

\author{
Kathleen A. Lehman
}

The collection development and management literature from 2011 and 2012 explores how libraries are making difficult collection choices with decreasing funds, competing needs for space, and a continually developing e-market. Digital content is no longer new in collection management, but some of the ways the content is chosen have changed; collection-building activities now include various models of patron-driven demand acquisitions. Other literature in this area examines how libraries are addressing their print and electronic collections with topics including open access materials, shared collection building, and weeding collections for repurposed space.

Kathleen A. Lehman (kalehman@uark .edu) is Head of the Physics Library at the University of Arkansas, Fayetteville.

Submitted July 5, 2013; tentatively accepted October 10, 2013 pending minor revision; revision submitted December 11, 2013; accepted for publication April 10, 2014.

The author offers her thanks to Library Resources and Technical Services for the award of an ALCTS grant and a special thank you to graduate assistant Amanda Schilling for her assistance in preparing this review.
To sum up the collection development and management literature published 1 in 2011-12, Liz Chapman, director of Library Services, London School of Economics and Political Science, does it best: "Our fundamental responsibilities in collection development have not changed, but our methods have."1 Much of the collection management and development literature in 2011 and 2012 focused on activities in response to two main factors: limited budgets and the need for more or redefined space. Both these factors have been a reality for many years, but projects that started at the beginning of the most recent recession, plus the continuing growth of the e-book industry and the availability of open access (OA) resources, are now more reported in the library literature. This paper reports on the development of these trends.

This overview does not include all available literature on collection management and development from 2011 and 2012, but it focuses on a significant portion of what has been written and identifies trends. Both EBSCO's Library, Information Science and Technology Abstracts (LISTA) and Library Literature and Information Science Full Text databases were searched for relevant literature. While there is significant overlap in the two databases, each contains unique journals, and most resources consulted for this review are from these databases. Additional searches were conducted using Google to gain information on various organizations and programs. The author also consulted several publishers' recent catalogs, including ALA Publishing (Neal-Schuman and the ALA Store) and Libraries Unlimited to find more relevant monographic publications than those titles retrieved from database searches. Most literature retrieved focused on practices and trends in academic libraries, and literature on other types of libraries was 
not purposefully excluded. Similarly, publications tended to focus on findings in the United States.

\section{Patron-Initiated Purchasing}

\section{Demand-Driven Acquisitions}

Many of the challenges that libraries face today are the same ones that libraries have always faced, but in a new form. Although no library has had sufficient funds to purchase everything it wanted, today's particularly slim budgets mean that librarians must focus on the main principle of basing collection decisions on patron needs. ${ }^{2}$ Librarians, knowing they must justify their spending and, in some cases, even the existence of their libraries, have become more judicious about how funds are spent, looking closely at what is being requested and what is used. ${ }^{3}$ They make professional decisions about purchasing materials, decisions that are based on several factors, including resource reviews, developments in various subject fields, statistics that include usage and age of a collection, how the current collections might be lacking, and patrons' needs. Librarians have always considered direct requests from patrons, but it is this last method that has seen progressively more emphasis as budgets become increasingly tight and each purchasing decision carries greater weight. Studies dating back to 1979 show that much of what is purchased using traditional acquisitions methods goes unused. ${ }^{4}$ Many libraries are responding to patrons by transferring some of the purchasing power directly to them through demand-driven acquisitions (DDA) or patrondriven acquisitions (PDA). (Note: For the remainder of this paper, the various processes of direct patron selection will be referred to as "DDA.") Rather than purchasing what librarians anticipate patrons want, libraries are purchasing the resources at the point at which it is used or requested by the patron. This shift is a change from the "just in case" model to "just in time," with the focus moving from collections to usage and the decisions moving from librarians to patrons. ${ }^{5}$ Even if a purchased resource is used only by the patron who made the request, it is still considered as a circulation; historically, many books in library collections never get that initial circulation. ${ }^{6}$ Additionally, subscribing to publishers' "Big Deal" bundles is a practice that is no longer viewed favorably. ${ }^{7}$ These bundled groupings of resources originally provided cost-effective ways for libraries to deliver access to large collections of information. As the prices of bundles continue to rise, librarians have found that the deals lack the flexibility to effectively balance their budgets. ${ }^{8}$ To fund DDA programs, many libraries start with one-time funds for pilot programs. Once the money is expended, they review the results to see what has been purchased, how much has been spent, and determine whether the program will continue. ${ }^{9}$
DDA programs are often used for e-book purchases, and suppliers (such as Yankee Book Peddler, more commonly known as YBP) provide records for a library to load into its catalog. The patron cannot tell the difference between an e-book that has been purchased by the library and one that is a part of a DDA program. When a patron searches the cata$\log$, these records show up in the results display side-by-side. In either case, when the patron clicks on the link embedded in the bibliographic record, the book opens on the vendor's platform. The library does not pay for the resource unless it is used by a patron, and typically after an agreed-on "trigger" is reached. ${ }^{10}$ The definition of this "trigger," or "use," varies by supplier but can be an activity such as staying on a page for five minutes or longer, navigating through a set number of pages, or downloading or printing a portion of the e-book. Many DDA programs will allow for a set number of uses before the e-book becomes a part of the library's permanent collection. The initial uses can be considered as short-term rentals with the rental price often set around 10 percent to 20 percent of the full price of the resource, depending on the publisher. ${ }^{11}$ After a few rentals (often two or three) of the same item, the library pays the full purchase price and has perpetual access to the e-book. Additional purchases for the same title may be triggered after a certain number of holds have been placed on the e-book. DDA programs eliminate the need to pay for materials that are not used. These programs, however, require libraries to abandon the concept of the perceived need for ownership, which can be difficult for those in the library world and for library supporters. ${ }^{12}$

\section{Interlibrary Loan as a Form of DDA}

Another example of DDA is through interlibrary loan (ILL) requests. ${ }^{13}$ In this case, when a request is placed to borrow a book from another library, the ILL department considers purchasing the item and adding it to the collection. Like the e-book DDA programs, purchasing resources based on ILL requests is another way to respond to patrons at their point of need. There are shipping charges associated with a physical ILL transaction, and some libraries have decided that purchasing the requested items is a better use of funds. Purdue University Libraries instituted this method of DDA in $2000 .{ }^{14}$ After reviewing circulation statistics, Purdue librarians found that books purchased through the DDA program were more likely to circulate than those purchased through traditional selection. ${ }^{15}$ This was true both when considering the initial circulation from the patron who requested the book through DDA and when considering subsequent circulations.

DDA programs are often mediated by librarians. Most libraries set a limit on the cost for a single item, define the call number range into which the item will fall, require that the title must have been published within the past few years 
or place other restrictions on loaded records or purchase requests to ensure that the acquisitions are aligned with the library's collection-building mission. Items that fall outside these parameters are either not loaded into the catalog or the request through ILL may be individually considered by a subject or collections librarian. Specifications from the DDA program of the State University of New York System initially stipulated that a purchased resource must cost fewer than $\$ 300$, be published in the past five years, could not duplicate a title owned by the libraries, and, since their program was through ILL, had to be likely to arrive within a short timeframe. ${ }^{16}$

\section{Print-on-Demand}

Print-on-demand, which is often provided using a machine like the Espresso Book Machine (EBM), is another ondemand program that adds books to a library's collection. ${ }^{17}$ The EBM contains the digital files for millions of books. At a user's request, a book is printed and bound in minutes while the patron waits. The book can then become a part of the library's collection or can be purchased by the patron. This kind of on-demand printing may also be used to preserve rare or fragile materials. ${ }^{18}$ A copy can be produced of materials from special collections to minimize the handling of the originals. The print-on-demand version of DDA has not become widely used in part because of the initial startup costs for the machine itself. The e-book and ILL methods of DDA take advantage of existing processes and resources and do not require an unwieldy initial financial investment. Ideally, the money is spent slowly as titles are requested and the investment is spread out over a longer period and can be defined by the institution's budgetary constraints and not the cost of equipment.

\section{"E" Growing Pains}

In their paper on the shared collection management of printed materials, Sandler et al. state, "As scholars increasingly rely upon electronic access to needed resources, these libraries-like libraries everywhere-are seeking ways to preserve access to the printed volume but at the same time redirecting resources - dollars, staff, and space-to the management of increasingly digital collections." ${ }^{\prime 19}$ Wilde and Level of Colorado State University address the shifting balance of print and digital: "The library as a building and place with immense physical collection is no longer the sustainable model. The availability of large amounts of electronic usage statistics has been pushing libraries toward a more numbers-based model of collection development, and the economic crisis accelerated the transition." ${ }^{20}$ This "transition" to "increasingly digital collections" is clearly reflected in monographs published during 2011and 2012. No Shelf Required was published in 2011 in response to the quickly increasing use of e-books and reading devices and is an attempt to help readers understand the e-book landscape. ${ }^{21}$ The following year, No Shelf Required 2 was published, calling e-books "mainstream." ${ }^{22}$ A sampling of titles from these years demonstrates how libraries' electronic collections are continuing to grow rapidly: Building and Managing E-Book Collections, Collection Development in the Digital Age, Managing Electronic Resources, and Electronic Resources Management in the Academic Library. ${ }^{23}$ In 2011, Amazon reported that its e-book sales had surpassed its print sales, and many publishers have experienced a substantial decrease in their print business. ${ }^{24}$ Yet, while there is an increasing push toward and availability of e-resources, there is still an audience for print. Faculty at many academic institutions rely on materials that are available digitally for their everyday research but are not yet comfortable with the idea of a library's collection being void of print. ${ }^{25}$ Text within e-books can be easily searched, users can adjust the text size to meet their needs, and books on a device do not increase the weight or space occupied in a book bag. Users, however, can be limited by a device's battery life, may have difficulty loading new content, and may find reading a screen more difficult than reading a printed page. ${ }^{26}$

Online databases are generally preferred for journal article access, but the preference for books continues to lean toward print over e-books. Subject matter or research area can also influence the preference of print or electronic. For example, many e-resources are available for the sciences, yet there are fewer for the arts. ${ }^{27}$ Library-provided e-resources in the arts are not as often used in part because of uncertainties in intellectual property rights and fair use and because of the relative ease of image-searching on the Internet, including Google Image Search. ${ }^{28}$ Libraries are finding that their patrons' preference for digital or print can vary and depends on the time, place, and purpose for access to the materials.

\section{Preservation Considerations}

With the purchase of physical items for a libraries' collection, the ownership and preservation responsibilities have been straightforward in that once an item is purchased, the library sets lending limits, decides whether to retain an item, or determines when an item needs further care (e.g., rebinding) to keep it in useable condition. With e-resources, much of the ownership rights, responsibility for preservation, and access restrictions are set by the publisher. In the past, one safeguard against information loss was that books were collected by multiple libraries. ${ }^{29}$ If an item were to be damaged at one library, there were other collections from which it could be borrowed. With e-resources, there is a different set of issues: What happens when the library no longer 
subscribes to or can pay for the platform through which the e-resource is accessed by patrons? What happens if the publisher or supplier of the e-resource ceases to exist ${ }^{20}$ What happens as software develops and the technology used to access a book's content is no longer supported? ${ }^{31}$ For the concern about the continued existence of a content publisher or provider, Portico works with publishers and libraries to preserve digital content. Portico, which is a service of Ithaka, has preserved e-journal content since 2005 and expanded its services to e-books in $2008 .^{32}$ As for what happens if a library no longer subscribes to content, some publishers now allow for post-cancellation access (PCA) via Portico. ${ }^{33}$ In 2012, there was a lack of PCA options, but as of the writing of this review, Portico reports that 88 percent of the e-journal content and 87 percent of the e-book content it preserves is available for PCA. ${ }^{34}$ Regarding outdated software, there is the preservation tactic of migrating content from one format to another. However, as with rebinding a physical item, this requires time and resources. With rebinding, often the need to care for items comes one at a time, while the need to reformat digital materials may affect a large portion of the collection all at once.

Another difficulty with libraries trying to preserve or access materials as freely as they would like is Digital Rights Management (DRM). DRM refers to a "set of 'technologies' that e-producers ... may employ to control access to and use of their copyrighted material, especially copying, by third parties. ${ }^{\prime 35}$ Restrictions can include limiting the number of simultaneous users who can access the content, limiting the number of pages that can be downloaded or printed, or limiting the type of device on which the content can be accessed. These technologies restrict libraries' ability to manipulate the content and therefore make digital migration difficult. Since libraries are unable to ensure preservation for perpetual access through migration on their own, the responsibility for preservation of the digital content rests with the publishers or through cooperative services such as Portico. ${ }^{36}$ Part of Portico's preservation plan and process is migration. ${ }^{37}$

\section{Ongoing and Future Costs}

An additional concern with e-books is ongoing and future costs. Since the information contained in e-books is stored on a publisher or vendor's server, many of them charge annually for continued access to the platform. Even though the library has paid for the digital item, it must pay an additional fee to ensure that patrons can use the platform to access the content. Additionally, the initial cost of purchase is an unsettled issue: sometimes digital is cheaper than print and sometimes the opposite is true, and allowing access by multiple users often drastically escalates the price. Without clear industry standards, publishers seem to be testing the prices the market is willing to tolerate. ${ }^{38}$
The e-book model has affected ILL. Print books can be shipped to another library through the mail; e-books licensing agreements typically limit access to directly affiliated users. ${ }^{39}$ E-books have the potential to alleviate some of the burdens of traditional ILL print lending, specifically the cost of shipping, the delay of lending caused by the need to physically move items, and the potential for materials to be returned damaged either from the shipping process or by a careless patron. ${ }^{40} \mathrm{~A}$ partnership between Ingram Content Group and OCLC Online Computer Library Center allows for short-term lending of e-books using WorldCat Resource Sharing and ILLiad Resource Sharing Management Software, which are the same tools many libraries use for traditional ILL. ${ }^{41}$ Some consortia, like TexShare and OhioLINK, make group e-book purchases rather than require each library to make individual purchases. ${ }^{42}$ While this is not an ILL model, it is an alternative, cost-effective way to provide a more diverse collection than if each library were separately purchasing for its local patrons.

\section{Open Access}

Open access (OA) has become a consideration in e-resources collection management. When referring to OA materials, most authors, researchers, and librarians are discussing research or scholarly information, such as a journal article, that is available freely on online for anyone to read. ${ }^{43}$ Interested individuals who might not be able to afford access to research publications can benefit from the availability of $\mathrm{OA}$ materials. For libraries, OA materials can be useful as inexpensive additions to their collections. OA does not mean that the publications are truly free; someone is paying the cost for the publication process. In many cases, the researchers pay for the article, either with support from their institutions or from the grants used to conduct the research. Publication fees can range from a few hundred to thousands of dollars. ${ }^{44}$ There are many different iterations of OA. For example, green OA refers to articles that are available via an open digital repository. Gold OA refers to journals that provide all content free for end users at the time of publication. Some publishers give authors the option to pay for publication, which creates a journal in which some of the articles are $\mathrm{OA}$ and some are not, while some other publishers provide content freely only after an embargo period. ${ }^{45}$

Once the publication of the material has been paid for, the financial barriers to access to the wider public are diminished, and OA publication can accelerate the research process. ${ }^{46}$ With information easily accessible, researchers can more quickly begin building on the published information. Regardless of whether the articles are freely available, they will not be useful if they are not easily found. Researchers may often turn to a web search engine to find resources, so making OA materials discoverable in library catalogs and in 
research databases is critical. ${ }^{47}$ Librarians should be aware of which OA titles are available and make choices regarding what to include in their libraries' catalog, their A-Z lists, or their database subscriptions to support their patrons' research.

It can be difficult to determine whether an OA publication is credible or not. Some OA journals have proven their quality: PLoS Biology, for example, has the highest impact factor rating in its field. ${ }^{48}$ Other OA publications are not as well known, and librarians and researchers may be concerned with the existence of predatory publishers. Predatory publishers produce $\mathrm{OA}$ journals that lack the rigorous review standards of higher-quality journals and will publish any article if the authors are willing to pay a fee. ${ }^{49}$ These publishers' websites are often vague or deceptive regarding fees associated with publishing or regarding licensing and copyright. ${ }^{50}$ They may trick authors into publishing by inviting papers and later billing them, and they are taking advantage of a system where researchers' careers depend heavily on how often they publish and on the success of their publications. Beall compared these journals with email spam. ${ }^{51}$ For librarians, the concern is to be aware of these types of predatory OA journals both so they do not include them in the libraries' catalogs and to keep their patrons informed about what are bona fide high-quality OA resources.

\section{Collaborative Collection Development and Storage Considerations}

More users are coming to expect libraries to be places of service and places to study rather than places that hold books, and library personnel are challenged to allocate space wisely. ${ }^{52}$ Past collection-building practices have left shelves filled to capacity, but not necessarily with current and quality resources. A big consideration in finding and redefining space includes evaluating, shifting, and transferring collections. Libraries often begin by evaluating journal runs, which are more likely to be available and to be used digitally than monographs. Faculty at academic institutions continue to grow more comfortable with e-only access, and many have come to expect the ease of e-access for journal articles. ${ }^{53}$ The preference for articles to be available digitally is clearly reflected in use data. As print use has steadily declined over the past several years, e-journal use continues to rise. ${ }^{54}$ Moving large journal runs is more efficient both in time and expense than dealing with monographs. ${ }^{55}$ Titles that are available through trusted providers like JSTOR and Portico are more likely to be moved to storage because librarians are confident that the materials will be easily available for their patrons into the foreseeable future.$^{56}$ The role of print materials, particularly journals, has become one of preservation rather than direct patron use. ${ }^{57}$
Another way that libraries are working to conserve space and money is by developing collection plans with partner libraries. These are formal agreements and programs developed and carried out by a group of libraries that see benefit in working together. ${ }^{58}$ Rather than focusing on local collections, libraries work together to create a fuller shared collection than any one of them could do alone. Although access for local patrons may not be as immediate as it would be if all material were owned locally, a large shared collection is more of a financial reality and the scope of the collection available is wider than any one library can house. Challenges arise from working together, including definitions of ownership, scope, and intent of the shared collection, funds available, and, if shared storage is involved, managing the workload of identifying and transferring items to a new location. ${ }^{59}$ One study gives the price difference between housing items in open stacks versus housing them in high density storage at $\$ 3.40$ per item per year, with open stacks being the more expensive option; shared storage can save space and money. ${ }^{60}$ Some of the high-density storage facilities that service multiple libraries include the Washington (DC) Research Consortium, the Research Collections and Preservation Consortium hosted by Princeton University, and the Five Colleges Library Depository in Amherst, Massachusetts. ${ }^{61}$ Trust between the participating libraries is a key element for these types of collection partnerships to be successful. Therefore most partnerships develop from existing consortia or similar networks that already work together. ${ }^{62}$ The "Cloud Library" project, for example, was started in 2009 following a discussion between several Association of Research Libraries (ARL) directors who wanted to examine the challenges and opportunities faced by academic libraries, including how to balance preservation with finding space and realizing financial efficiency in managing collections. ${ }^{63}$

As more libraries begin to share collections and deposit materials, the measurement of the size of a libraries' collection no longer equates with its quality. A more current measure of a library's worth is the amount of unique material to which its patrons have access. ${ }^{64}$ Chadwell cites several sources that state the value of a collection no longer comes from the number of volumes held but rather in the effect those resources have and how they influence and encourage education; a library's value is in the services and expertise it provides to its user group. ${ }^{65}$ Collective depositories and repositories provide some assurance of preserving rare and unique items. ${ }^{66}$ Some collaborative agreements come not from sharing storage facilities but from a certain number of institutions agreeing to retain and preserve particular materials, like a run of a journal, so that other institutions can remove their copies and reclaim space. ${ }^{67}$ The previously mentioned Cloud Library project found that very few print collections were needed to duplicate material that had been digitized by the HathiTrust. ${ }^{68}$ As libraries continue to look 
beyond their own stacks and to find ways to work productively with others, the shift in mindset from ownership to providing access will also continue.

\section{Tending to the Collection: Weeding}

Although education programs in library science cover collection-development polices and weeding practices, sometimes the reality of the library as a workplace does not reflect these "best practices." ${ }^{\prime \prime 9}$ The argument has been made that libraries spend far too much of their budgets and personnel energy on using the library as a museum when the focus needs to be on the library as a place of creative discovery and service.$^{70}$ Others believe that preservation of information (not necessarily in print) is a core value of libraries. ${ }^{71}$ Some libraries resist weeding collections because of the public's perception of the library as safe places for materials. ${ }^{72}$ The public may view weeding as a threat to their access to information. In reality, a well-maintained, well-pruned collection is far more useful than one filled with out-of-date or unused materials. Many libraries are returning to the very important task of weeding as they run out of space and face the costs of storage and maintenance of their physical collections. They are running out of space not just for new acquisitions but also for the patrons who use the library space. This is reflected in the William F. Ekstrom Library at the University of Louisville where "in addition to new financial considerations, much of Ekstrom's first floor, home of the reference collection, has been repurposed as a learning commons. ${ }^{, 73}$ Similar space considerations were taken into account at American University Library where the authors noted "the library could gain valuable room for growth in the monographic collection and still allow for space improvements designed to make the building more attractive to students and researchers." ${ }^{\text {"74 }}$ Schonfeld's "What to Withdraw" is a study that provides recommendations and tools for weeding collections based in part on the 2009 Ithaka S+R Faculty Survey, which includes responses from more than 3,000 participants. ${ }^{75}$ By listening to what patrons are comfortable using and looking at shifting attitudes, the report suggests how libraries can respond to the need to weed. The report describes the ideal situation in which something could be withdrawn: a situation where access and preservation are ensured by other sources. ${ }^{76}$ Schonfeld suggests that with well-digitized journals, if there are two verified print copies in trusted repositories, other libraries can weed their own print copies. ${ }^{77}$ One institution that has renewed and revalidated the weeding process is the library at Concordia College in Moorhead, Minnesota. Although there were previous uncoordinated efforts to weed some of the collection, the Carl B. Ylvbisaker Library had nearly reached capacity. ${ }^{78}$ The librarians made an organized effort to weed their collection, starting in 2007. They developed a plan to work in teams and review assigned sections of the collection over the following eight years. When the authors wrote about the weeding project, the procedures had been in place for four years and the project was still successful..$^{79}$ In addition to relieving the space concerns, the authors reported that the process resulted in a better understanding of the collection and created a better working environment as people collaborated on this project.

Shared collection storage projects mentioned above and other shifting projects provide good opportunities to weed. Since each transferred book must be handled, reviewing the items as part of the same project can save time and money. Combining these projects saves money by reducing the costs of storing unwanted materials and anticipates future costs when space constraints may force a library to review its physical collections again. One article reports that it is much easier to weed before the materials go into storage.$^{80}$ In that particular case, the Grand Valley State University Libraries reported on the challenges of weeding the law library collection, which was held in an automated storage and retrieval system (ARS). ${ }^{81}$ Materials were arranged by size rather than by call number, and they were retrieved by barcode number. One might find a wide array of call numbers in a bin of materials, which makes weeding in a specific topic extremely difficult. The authors gave a sound piece of advice: "Completely and aggressively weed collections before moving them into an ARS." ${ }^{\prime 2}$

Weeding has always been an important component of collection management, but the nonphysical nature of electronic collections may seem to take away some of the urgency that is apparent in traditional collections. With physical collections there is a real need for physical shelf space; unused items must be moved to make way for new acquisitions. Weeding physical collections means making a collection more relevant to the patrons as they search the shelves and catalog for the materials. Some of these considerations continue to be relevant for e-collections. Libraries may not need the shelf space, but clearing out unused materials makes a patron's searching experience better by reducing the number of old and irrelevant records the patrons must wade through in their search results to find what they really want. ${ }^{83}$ In some cases, like the DDA programs in which item records are loaded into the library's catalog for patron discovery, some of the weeding is part of the cycle: if items are not used and not purchased after a given amount of time, the records are automatically removed. When librarians are considering e-items to remove, reference material that has been superseded by new editions and materials that have not circulated (i.e., been accessed) during a set period should be removed from the collection. ${ }^{84}$ Suppressed records are not maintenance free as they occupy digital space and require personnel time to maintain. In theory, the weeding process 
for e-books should be as simple as deleting the record from the library's catalog, but the practice of weeding e-books is not yet well supported by all providers' platforms. Often, once purchased within the vendor's platform, there is no way to remove the record directly; librarians must work through customer service to weed out unwanted or outdated items. ${ }^{85}$

\section{Conclusion}

As libraries and publishers navigate the landscape of a growing e-resources market, librarians continue to look for ways to handle their physical collections and spaces. By using DDA programs, libraries are building collections that are based on the patrons' direct needs. While there are plenty of uncertainties in the world of e-materials in terms of rights and preservation, libraries and patrons are becoming more comfortable with and reliant on collections that are available when and where they are needed. By working together, libraries are finding ways to pare down their collections to save and repurpose space, to use money more wisely, to weed collections so they have more focus, and to help with preservation efforts. The trends that are apparent in the literature from the 2011 and 2012 have grown out of the constant need to balance space, budgets, patrons' requests, and the desire to preserve.

\section{References}

1. Liz Chapman, forward to Collection Development in the Digital Age, ed. Maggie Fieldhouse and Audrey Marshall (London: Facet, 2012), vii.

2. G. Edward Evans and Margaret Zarnosky Saponaro, Collection Management Basics, 6th ed. (Santa Barbara, CA: Libraries Unlimited, 2012), 5, 69, 97-98.

3. Michelle Wilde and Allison Level, "How to Drink from a Fire Hose without Drowning: Collection Assessment in a Numbers-Driven Environment," Collection Management 36, no. 4 (2011): 218, 221.

4. Kenning Arlitsch, "The Espresso Book Machine: A Change Agent for Libraries," Library Hi Tech 29, no. 1 (2011): 64.

5. Lars Leon and Nancy Kress, "Looking at Resource Sharing Costs," Interlending \& Document Supply 40, no. 2 (2012): 82.

6. Tim Collins, "The Current Budget Environment and Its Impact on Libraries, Publishers and Vendors," Journal of Library Administration 52, no. 1 (2012): 33-34; H. Austin Booth and Kathleen O'Brien, "Demand-Driven Cooperative Collection Development: Three Case Studies from the USA," Interlending \& Document Supply 39, no. 3 (2011): 148.

7. Faye A. Chadwell, "What's Next for Collection Management and Managers? Sustainability Dilemmas," Collection Management 37, no. 1 (2012): 5; Collins, "The Current Budget Environment," 24.
8. Dennis Dillon, "Texas Demand-Driven Acquisitions: Controlling Costs in a Large-Scale PDA Program," in PatronDriven Acquisitions: History and Best Practices, ed. David A Swords (Berlin: De Gruyter Saur, 2011), 159.

9. Booth and O'Brien, "Demand-Driven Cooperative Collection Development," 153-54.

10. Lindsey Schell, "The Academic Library E-Book," in No Shelf Required: E-Books in Libraries, ed. Sue Polanka (Chicago: American Library Association, 2011), 76-78; Collins, "The Current Budget Environment," 34 .

11. Carolyn Morris and Lisa Sibert, "Acquiring E-Books," in No Shelf Required: E-Books in Libraries, ed. Sue Polanka, (Chicago: American Library Association, 2011), 100-101.

12. Steven R. Harris, "Mortgaging our Future on Ownership, Or, the Pleasures of Renting," Against the Grain 23, no. 4 (2011): 28-32.

13. Booth and O'Brien, "Demand-Driven Cooperative Collection Development," 148-50.

14. Judith M. Nixon and E. Stewart Saunders, "A Study of Circulation Statistics of Books on Demand: A Decade of PatronDriven Collection Development, Part 3," in Patron-Driven Acquisitions: Current Successes and Future Directions, ed. Judith M. Nixon, Robert S. Freeman, and Suzanne M. Ward (New York: Routledge, 2011), 33-43.

15. Ibid., 37-39, 42 .

16. Booth and O'Brien, "Demand-Driven Cooperative Collection Development," 153.

17. Arlitsch, "The Espresso Book Machine," 62-63, 65.

18. Ibid., 66-67.

19. Mark Sandler et al., "CIC Co-Investment to Protect Print Research Library Collections in the Midwestern United States," Collection Management 37, no. 3-4 (2012): 238.

20. Wilde and Level, "How to Drink from a Fire Hose Without Drowning," 229.

21. Sue Polanka, ed., No Shelf Required: E-Books in Libraries (Chicago: American Library Association, 2011), xi-xiii.

22. Sue Polanka, ed., No Shelf Required 2: Use and Management of Electronic Books (Chicago: American Library Association, 2012), ix.

23. Richard Kaplan, ed., Building and Managing E-Book Collections: A How-To-Do-It Manual for Librarians (Chicago: Neal-Schuman, 2012); Maggie Fieldhouse and Audrey Marshall, ed., Collection Development in the Digital Age (London: Facet, 2012); Ryan O. Weir, ed., Managing Electronic Resources (Chicago: ALA Techsource, 2012); Karin Wikoff, Electronic Resources Management in the Academic Library (Santa Barbara, CA: Libraries Unlimited, 2012).

24. Fern M. Cheek and Lynda J. Hartel, "The Electronic BookBeginnings to the Present," in Building and Managing E-Book Collections: A How-To-Do-It Manual for Librarians, ed. Richard Kaplan (Chicago: Neal-Schuman, 2012), 4; Collins, "The Current Budget Environment," 24.

25. Laurel Ivy Sammonds and Ross Housewright, "Print 
Collections Management in the Wake of Digitization," Serials Librarian 61, no. 2 (2011): 194.

26. Cheek and Hartel, "The Electronic Book," 5.

27. Tamsyn Bayliss, "Viewpoint: What is the Future of Art Libraries?" Art Libraries Journal 37, no. 1 (2012): 4.

28. Virginia Rutledge, "Viewpoint: Legalizing the Practice of Art History," Art Libraries Journal 37, no. 2 (2012): 3; Victoria Brown and Catherine Worrall, "Art in the Digital Age: A Comparative Study of the Adoption of Electronic Visual Resources in the UK, Ireland and North America," Art Libraries Journal 37, no. 3 (2012): 23-25; Mary Kandiuk, "Digital Images in Teaching and Learning at York University: Are the Libraries Meeting the Needs of Faculty Members in Fine Arts?" Evidence Based Library \& Information Practice 7, no. 2 (2012): 25.

29. Amy Kirchhoff, "E-Book Preservation: Business and Content Challenges," in No Shelf Required 2: Use and Management of Electronic Books, ed. Sue Polanka (Chicago: American Library Association, 2012), 72.

30. Vickery Bowles and Linda Hazzan, "Balancing Patron Demand for all Formats," Public Libraries 51, no. 1 (2012): 40.

31. Kirchhoff, "E-Book Preservation," 72.

32. "Portico," Portico, accessed November 1, 2013, www.portico. org/digital-preservation.

33. "Post Cancellation Access," Portico, accessed November 1, 2013, www.portico.org/digital-preservation/services/reliableaccess/post-cancellation-access.

34. Ibid.; Magaly Bascones, "JISC Collections: Post-Cancellation Entitlement Registry Scoping Project," Collaborative Librarianship 4, no. 3 (2012) 85-95.

35. Evans and Saponaro, Collection Management Basics, 239.

36. Nadia J. Lalla, "E-Book Publishing-the View from the Library," in Building and Managing E-Book Collections: A How-To-Do-It Manual for Librarians, ed. Richard Kaplan (Chicago: Neal-Schuman, 2012), 24-26, 31.

37. Michael Seadle, "Archiving in the Digital World: The Scholarly Literature,” Library Hi Tech 30, no. 2 (2012): 372.

38. Ibid., 25-26, 34.

39. Leon and Kress, "Looking at Resource Sharing Costs," 81.

40. Schell, "The Academic Library E-Book," 90-91.

41. "OCLC and Ingram to Offer New Option for Access to e-Books," OCLC Online Computer Library Center, press release, April 11, 2011, www.oclc.org/news/releases/2011/201116.en.html; “Enhancement to Ingram's MyiLibrary Short-Term E-book Loan Access," OCLC Online Computer Library Center, press release, November 20, 2012, www.oclc.org/news/announcements/2012/announcement53. en.html.

42. Schell, "The Academic Library E-Book," 83-84.

43. Walt Crawford, Open Access: What You Need to Know Now (Chicago: American Library Association, 2011), 1, 11.

44. Cheryl S. Collins and William H. Walters, "Open Access
Journals in College Library Collections," in Serials Collection Management in Recessionary Times, ed. Karen Lawson, (New York: Routledge, 2011), 64-65.

45. Crawford, Open Access: What You Need to Know Now, $15-23$.

46. Ibid., 1,4 .

47. Collins and Walters, "Open Access Journals in College Library Collections,” 59, 65, 72, 74.

48. Crawford, Open Access, 28.

49. Jeffrey Beall, "Predatory Publishers are Corrupting Open Access," Nature 489, no. 7415 (2012): 179.

50. Jeffrey Beall, "Five Scholarly Open Access Publishers," Charleston Advisor 13, no. 4 (2012): 5-10.

51. Beall, "Predatory Publishers," 179.

52. William Joseph Thomas, "Trusting Digital Preservation for Print Collection Management, or How Librarians Should Learn to Stop Worrying and Love the 'E', 'Against the Grain 23, no. 4 (2011), 24.

53. Roger C. Schonfeld, "What to Withdraw? Print Collection Management in the Wake of Digitization," Serials Librarian 60, no. 1-4 (2011): 141-42.

54. Robert K. Reeves and Kari Schmidt, "Radical Relocation: Adapting Print Collections to an E-Centric World," Serials Librarian 61, no. 3-4 (2011), 412-29.

55. Sandler et al., "CIC Co-Investment," 257.

56. Thomas, "Trusting Digital Preservation for Print Collection Management," 24; Reeves and Schmidt, "Radical Relocation," 412-15.

57. Schonfeld, "What to Withdraw?" 141-45.

58. Robert H. Kieft and Lizanne Payne, "Collective Collection, Collective Action," Collection Management 37, no. 3-4 (2012), 137-52.

59. Susanne K. Clement, "From Collaborative Purchasing Towards Collaborative Discarding: The Evolution of the Shared Print Repository," Collection Management 37, no. 3-4 (2012): 153-67.

60. Sam Demas and Wendy Lougee, "Shaping a National Collective Collection: Will Your Campus Participate?” Library Issues 31, no. 6 (2011): 2.

61. Ibid.

62. Kieft and Payne, "Collective Collection, Collective Action," 142.

63. Constance Malpas, Cloud-Sourcing Research Collections: Managing Print in the Mass-Digitized Library Environment (Dublin, OH: OCLC Research, 2011), 13-14, accessed April 26, 2013, www.oclc.org/research/publications/ library/2011/2011-01.pdf.

64. Kieft and Payne, "Collective Collection, Collective Action," 140.

65. Faye A. Chadwell, "What's Next for Collection Management and Managers? Assessing the Value of Collection Services," Collection Management 37, no. 2 (2012): 58-64.

66. Kieft and Payne, "Collective Collection, Collective Action," 
$137,148-49$.

67. Demas and Lougee, "Shaping a National Collective Collection" $1-4$.

68. Malpas, Cloud-Sourcing Research Collections, 9.

69. Carmelita Pickett et al., "Revisiting an Abandoned Practice: The Death and Resurrection of Collection Development Policies," Collection Management 36, no. 3 (2011): 165-81.

70. Harris, "Mortgaging our Future on Ownership," 28.

71. Evans and Saponaro, Collection Management Basics, 247-72.

72. Kieft and Payne, "Collective Collection, Collective Action," 147.

73. Robert Detmering and Claudene Sproles, "Reference in Transition: A Case Study in Reference Collection Development," Collection Building 31, no. 1 (2012): 19.

74. Reeves and Schmidt, "Radical Relocation," 413.

75. Sammonds and Housewright, "Print Collections Management in the Wake of Digitization," 193-95; Schonfeld, "What to Withdraw?"141-45.
76. Schonfeld, "What to Withdraw?" 141-45.

77. Ibid., 144.

78. Amy K. Soma and Lisa M. Sjoberg, "More Than Just LowHanging Fruit: A Collaborative Approach to Weeding in Academic Libraries," Collection Management 36, no. 1 (2011), $17-28$.

79. Ibid.

80. Patricia Bravender and Valeria Long, "Weeding an Outdated Collection in an Automated Retrieval System," Collection Management 36, no. 4 (2011), 237-45.

81. Ibid.

82. Ibid., 244.

83. Alice Crosetto, "Weeding E-Books," in No Shelf Required 2: Use and Management of Electronic Books, ed. Sue Polanka (Chicago: American Library Association, 2012), 95-96.

84. Ibid., 96-97.

85. Ibid., 99-100; Alene E. Moroni, "Weeding in a Digital Age," Library Journal 137, no. 15 (2012), 26-28. 